\title{
Fitólitos como indicadores de mudanças ambientais durante o Holoceno na costa norte do estado do Espírito Santo (Brasil)
}

\section{Phytoliths as indicators of environmental changes during the Holocene in the northern coast of the Espirito Santo State (Brazil)}

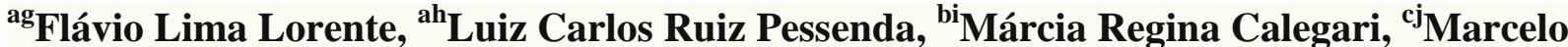 \\ Cancela Lisboa Cohen, ${ }^{\mathrm{dk}}$ Dilce Rossetti, ${ }^{\mathrm{el}}$ Paulo César Fonseca Giannini, ${ }^{\text {am Antonio Alvaro }}$ \\ Buso Junior, ${ }^{\text {dn }}$ Darciléa Ferreira de Castro, ${ }^{\text {co }}$ Marlon Carlos França, ${ }^{\text {ap José Albertino }}$ \\ Bendassolli, ${ }^{\text {fq }}$ Kita Macario
}

\begin{abstract}
${ }^{\mathrm{a} C}$ Centro de Energia Nuclear na Agricultura - Universidade de São Paulo, ${ }^{\mathrm{b}}$ Universidade Estadual do Oeste do Paraná, ${ }^{\mathrm{c}}$ Universidade
\end{abstract} Federal do Pará, ${ }^{\mathrm{d}}$ Instituto de Pesquisas Espaciais, ${ }^{\mathrm{e}}$ Universidade de São Paulo, ${ }^{\mathrm{f}}$ Universidade Federal Fluminense

g flimalorente@yahoo.com.br, ${ }^{\mathrm{h}}$ pessenda@cena.usp.br, ${ }^{\mathrm{i}}$ marciareg_calegari@ hotmail.com, ${ }^{\mathrm{j}}$ mcohen80@ hotmail.com,

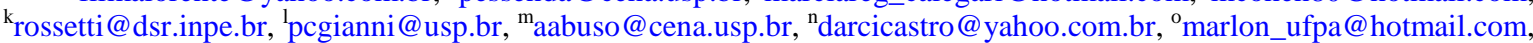

pjab@ cena.usp.br, ${ }^{\mathrm{q}} \mathrm{kita} @$ if.uff.br

\section{Resumo}

Um testemunho de 12 metros de profundidade e idade de $\sim 4260$ anos cal AP na sua base foi coletado na planície deltaica do litoral norte do estado do Espírito Santo. Esse trabalho teve como principal objetivo a caracterização do conjunto de fitólitos, auxiliado pelas fácies sedimentares, dados isotópicos $(\mathrm{C}$ e $\mathrm{N})$ e datações ${ }^{14} \mathrm{C}$ para reconstituir o paleoambiente. Os valores de carbono orgânico total - COT $(0,16 \%$ a $3,28 \%)$, nitrogênio total - $\mathrm{N}$ total $(0,01 \%$ a $0,09 \%), \delta^{13} \mathrm{C}(-4,25 \%$ a $-28,06 \%), \delta^{15} \mathrm{~N}(-6,19 \%$ a $15,75 \%$ ) e da razão $\mathrm{C} / \mathrm{N}(7,8$ a 99$)$ mostraram em linhas gerais que a matéria orgânica sedimentar foi originada a partir de fitoplâncton, e da mistura de plantas $\mathrm{C}_{3}$ e $\mathrm{C}_{4}$. A análise de fitólitos foi efetuada ao longo de 1,50 metros do perfil, e a partir dos agrupamentos por similaridade foi possível o estabelecimento de três intervalos que refletem mudanças na vegetação e provavelmente no clima a partir de $\sim 7589$ anos cal AP. No intervalo 1 ( 7589 anos cal AP a 5441 anos AP - idade interpolada), a assembléia fitolítica e os índices estatísticos de fitólitos calculados refletem uma vegetação composta pela mistura de árvores e gramíneas $\mathrm{C}_{3}$ e $\mathrm{C}_{4}$, semelhante e/ou comparável à vegetação de restinga, provavelmente sob clima quente e úmido. A análise de fitólitos do intervalo 2 ( 5441 anos AP - idade interpolada a $\sim 143$ anos cal AP) sugeriu a presença de uma vegetação em mosaico provavelmente constituída por diferentes formações da restinga, sob influência de clima quente e sazonal, com períodos de estresse hídrico. A diminuição da densidade arbórea, assinalada pelo índice D/P, e a formação da vegetação semelhante à atual, herbácea e com sinais de antropização, ocorreu nos últimos 200 anos (Intervalo 3), sob clima quente e úmido. Os dados de fitólitos são inéditos para a costa do Espírito Santo e mostram o potencial destes bioindicadores em estudos de reconstituição paleoambiental.

Palavras-chave: Holoceno; paleovegetação; planície costeira; fitólitos.

\begin{abstract}
A 12 meters core dated at $\sim 47260$ cal years BP was collected in the deltaic plain of the northern coast of the Espírito Santo State. The main objective of this study was to characterize the phytoliths in association with lithofacies, stable isotopes $(\mathrm{C}$ and $\mathrm{N})$ and radiocarbon dating, in order to reconstruct the paleoenvironment. The values of total organic carbon - TOC $(0.16 \%$ to $3.28 \%)$, total nitrogen - TN ( $0.01 \%$ to $0.09 \%), \delta^{13} \mathrm{C}(-4.25 \%$ o to $-28.06 \%), \delta^{15} \mathrm{~N}(-6.19 \%$ o to $15.75 \%$ ) and $\mathrm{C} / \mathrm{N}$ (7.8 to 99$)$ indicate that the sedimentary organic matter was originated from phytoplankton and $\mathrm{C}_{3}$ and $\mathrm{C}_{4}$ plants. The phytoliths analysis was performed along 1.50 meters of core, and through the groups generated by similarity was possible to establish three intervals that reflect changes in the vegetation and probably in the climate from $\sim 7589$ cal years BP. During the interval $1(\sim 7589$ cal years BP to $\sim 5441$ years BP interpolated age), the phytolith assemblage and the statistical index indicated that the vegetation was composed by trees and $\mathrm{C}_{3}$ and $\mathrm{C}_{4}$ grasses. The vegetation was similar and/or comparable to "restinga" and the climate probably was warm and humid. Phytolith analysis in the interval $2(\sim 5441$ years BP interpolated age to $\sim 143$ cal years BP) suggested the presence of a vegetational mosaic with different phytophysiognomies of "restinga". The climate was warm and seasonal, beyond periods of water stress. The decrease in the tree density indicated by D/P index and the formation of modern vegetation, which is herbaceous and anthropized, occurred in the last 200 years (Interval 3) under warm and humid
\end{abstract}


conditions. This data set about phytoliths is unpublished to the coast of Espírito Santo State and demonstrates the potential of these microfossils in studies of paleoenvironmental reconstruction.

Key-words: Holocene; paleovegetation; coastal plain; phytoliths.

\section{Introdução}

Os fitólitos (silicofitólitos ou opala fitobiogênica) são partículas de sílica amorfa que se acumulam em torno ou dentro das células dos tecidos vegetais (Rovner 1971, Thorn 2004). Resultam de um processo de biomineralização com controle biológico, ou seja, por mediação da matriz orgânica. As plantas constroem uma estrutura ou molde onde se introduzem os íons e ali são precipitados e cristalizados (Piperno 2006). A sílica é absorvida do solo através do sistema radicular das plantas, primeiro na forma de ácido monosilícico $\left(\mathrm{H}_{4} \mathrm{SiO}_{4}\right)$, polimerizando-se seguidamente no vegetal para gel e finalmente em fitólitos (Esptein 1994). Uma vez que o ácido monosilícico entra nos tecidos das plantas, ocorre o processo de polimerização e formação de depósitos de dióxido de sílica (Piperno 1988).

A produção (quantidade e variedade) e o grau de desenvolvimento dos diferentes tipos de fitólitos (morfotipos) nas plantas dependem de vários fatores genéticos e ambientais, tais como o clima, o ambiente onde a planta cresce e se desenvolve, a disponibilidade de água no solo, bem como características específicas das plantas como idade e afinidade taxonômica (Piperno 2006).

Uma vez que alguns morfotipos são específicos de determinadas famílias e subfamílias, quando preservados em solos e/ou sedimentos, podem permitir a identificação das plantas que os produziram (Piperno 2006). Dessa forma, um conjunto de fitólitos ou assembléia fitolítica pode caracterizar uma formação vegetal, representando um importante conjunto de dados para estudos que visam à reconstituição paleoambiental.

Reconstituições paleoambientais, visando o estudo do clima e da vegetação pretéritas na costa brasileira, têm sido realizadas principalmente com base em análises polínicas e isotópicas em solos e sedimentos (e.g. Amaral et al. 2012, Pessenda et al. 2012, Buso Junior et al. 2013a,b, França et al. 2013). A costa brasileira apresenta uma variedade de fitofisionomias vegetais que evoluíram sobre a influência do clima, da geomorfologia e das variações do nível relativo do mar durante o Holoceno. Dentre as diferentes fitofisionomias vegetais que ocorrem ao longo da costa brasileira, formações herbáceas, constituídas em grande parte por gramíneas, são abundantes. Entretanto, a análise polínica restringe a identificação destas gramíneas apenas em nível de família. Dessa forma, o uso dos fitólitos se torna essencial, uma vez que esses bioindicadores podem fornecer dados paleoambientais como a densidade da cobertura arbórea e a distinção entre gramíneas $\mathrm{C}_{3}$ e $\mathrm{C}_{4}$ (Lu \& Liu 2003).

Nas últimas décadas, diversos estudos referentes às mudanças da vegetação e clima pretéritos vêm sendo desenvolvidos com base nas assembléias fitolíticas preservadas em solos e sedimentos. No entanto, tais estudos se restringem em sua maioria ao Hemisfério Norte (e.g. Fredlund \& Tieszen 1994, Kelly 1998, Blinnikov et al. 2002, Strömberg et al. 2007) e ao continente africano (e.g. Alexandre et al. 1997, Barboni et al. 1999, Scott 2002). Na América Central e no continente sul-americano, as análises fitolíticas referem-se principalmente no que tange a estudos sobre a origem da agricultura, coleções de referência e aspectos arqueológicos e pedológicos (e.g. Piperno 1991, Pearsall et al. 2003, Trombold \& IsradeAlcantara 2005, Osterrieth et al. 2009, Watling \& Iriarte 2013), sendo ainda poucos estudos voltados para a reconstituição da vegetação e clima passados (e.g. Iriarte 2006, Gutiérrez et al. 2011).

No Brasil, os primeiros trabalhos relacionados aos fitólitos foram de caráter morfológico referente às espécies de gramíneas do bioma Cerrado (e.g. Sendulsky \& Labouriau 1966, Campos \& Labouriau 1969). No entanto, somente nas últimas duas décadas estudos de reconstituição paleoambiental para o Quaternário do Brasil utilizando os fitólitos como bioindicadores foram publicados (e.g. Piperno \& Becker 1996, Alexandre et al. 1999, Borba-Roschel et al. 2006, Calegari 2008, Calegari et al. 2013, Coe et al. 2013, 2014a,b,c, Parolin et al. 2014). Embora os fitólitos sejam importantes indicadores paleoambientais, as publicações sobre este tema no Brasil são ainda escassas. Nesse contexto, o objetivo principal deste trabalho é estudar as assembléias fitolíticas de um testemunho sedimentar costeiro, com o intuito de ajudar na reconstituição da história das paisagens e do clima no litoral norte do estado do Espírito Santo (ES) durante o Holoceno.

\section{2. Área de estudo}

\subsection{Contexto Geológico e Geomorfológico}

Os depósitos sedimentares analisados estão localizados na Bacia do Espírito Santo. Esta bacia está situada na região costeira $\left(20.000 \mathrm{~km}^{2}\right)$ e na plataforma continental $\left(200.000 \mathrm{~km}^{2}\right)$, e se estende sob a planície costeira atual, plataforma e talude continental do leste do Brasil, mais especificamente no ES. Está delimitada a sul com a Bacia de Campos, através do Alto de Vitória, e a norte com a Bacia de Mucuri. É uma bacia marginal cuja evolução tectônica e sedimentar está relacionada à separação do supercontinente Gondwana (Neocomiano) e à abertura do oceano Atlântico Sul com a separação das placas Sul-americana e Africana (Lisboa 2006, França et al. 2007). Para o Quaternário, os sedimentos descritos para a bacia correspondem aos de planície, próximos à foz do Rio São Matheus e do Rio Doce, além dos cordões litorâneos ao longo da costa (França et al. 2007). Os depósitos sedimentares 
acumulados durante as várias etapas da evolução quaternária são característicos de ambientes marinhos, flúvio-marinhos, lagunares e eólicos (IBGE 1987).

Do ponto de vista fisiográfico, o litoral norte do estado do Espírito Santo pode ser caracterizado através de três compartimentos geomorfológicos (figura 1), que fornecem à região uma paisagem bem definida: (1) cadeia de montanhas com rochas pré-cambrianas na porção oeste, (2) a planície de tabuleiros com terraços sobre depósitos da Formação Barreiras a leste da região serrana, e a (3) planície quaternária costeira nas áreas mais baixas ao longo do litoral. A planície costeira é drenada pelos cursos d'água da região, tendo os rios São Matheus e Doce papel fundamental na sedimentação quaternária (Suguio \& Martin 1981, Suguio et al. 1982).

\subsection{Vegetação e clima}

A vegetação da região norte do estado do Espírito Santo é constituída basicamente pela Floresta Ombrófila Densa das Terras Baixas e pelas Formações Pioneiras (figura 1). A Floresta Ombrófila Densa das Terras Baixas, também conhecida como Floresta (Mata) dos Tabuleiros, ocorre sobre os terrenos cenozóicos com depósitos arenosos e argilo-arenosos da Formação Barreiras ao longo do litoral, não atingindo altitudes superiores a 200 metros. As áreas das formações pioneiras compreendem uma faixa de largura variável, praticamente contínua ao longo do litoral, cobrindo os terrenos holocênicos na região. Estas formações possuem diversas fisionomias que são dependentes das condições ambientais, podendo ter influência marinha, flúvio-marinha ou fluvial (IBGE 1987).

O clima para a região, segundo a classificação de Köppen (1948), é do tipo Aw, ou seja, tropical úmido, com inverno seco e verão chuvoso. O clima regional é sazonal, com a estação chuvosa durante os meses de verão e a estação seca entre os meses de Junho a Setembro. A média anual de precipitação é de 1215 mm e a temperatura média anual de $23{ }^{\circ} \mathrm{C}$ (Buso Junior et al. 2013a).

\section{Material e Métodos}

\subsection{Amostragem}

As amostras sedimentares foram obtidas por meio do uso de uma sonda a percussão, modelo COBRA $m \mathrm{kl}$ (COBRA Directional Drilling Ltd., Darlington, UK). O testemunho sedimentar foi coletado na margem da Lagoa Bonita $\left(19^{\circ} 10^{\prime} 53\right.$ "S $\left./ 39^{\circ} 51^{\prime} 55^{\prime \prime} \mathrm{W}\right)$, que é um lago de água doce situado no baixo curso do rio Barra Seca, distante cerca de $30 \mathrm{~km}$ do rio Doce e $15 \mathrm{~km}$ do mar (Cohen et al. 2014). O furo de sondagem alcançou a profundidade de 12 metros, sendo que o testemunho coletado (Li01) foi devidamente fotografado e as fácies sedimentares descritas quanto à litologia, textura, estruturas sedimentares, conteúdo fossilífero e arranjo arquitetural (Miall 1978, Harper 1984, Walker 1992).

Foram selecionadas 102 amostras ao longo do testemunho visando registrar todas as variações faciológicas observadas. As amostras foram coletadas e submetidas às análises de fitólitos e isótopos de $\mathrm{C}$ e $\mathrm{N}$. As amostras foram armazenadas em sacos plásticos, identificadas quanto à profundidade e código do testemunho, e acondicionadas em refrigeração no Laboratório de ${ }^{14} \mathrm{C}$ do CENA-USP. Paralelamente a esta amostragem, foram separadas doze amostras para a datação ${ }^{14} \mathrm{C}$.

\subsection{Análise elementar e isotópica de $\mathrm{C}$ e $\mathrm{N}$}

A aplicação dos isótopos de carbono se baseia na diferença de composição de $\delta^{13} \mathrm{C}$ em plantas $\mathrm{C}_{3}$ e $\mathrm{C}_{4}$. Valores de $\delta^{13} \mathrm{C}$ em plantas $\mathrm{C}_{3}$ variam de $-32 \%$ a $20 \%$, enquanto que em plantas $\mathrm{C}_{4}$ variam de $-17 \%$ o a 9\%o (Meyers 1997). Dessa forma, variações no $\delta^{13} \mathrm{C}$ podem indicar mudanças na vegetação passada diante de condições de maior ou menor umidade, devido às diferenças nas preferências ecológicas entre as plantas $\mathrm{C}_{3}$ e $\mathrm{C}_{4}$. Valores de $\delta^{15} \mathrm{~N}$ são usados para distinguir as fontes da matéria orgânica sedimentar, sendo que valores de $\sim 8,5 \%$ são encontrados para algas e $\sim 0,5 \%$ para plantas terrestres (Meyers 1997). Os valores de $\mathrm{C} / \mathrm{N}$ em sedimentos podem ser usados para distinguir os dois principais tipos de matéria orgânica, a sem estrutura celulósica $(\mathrm{C} / \mathrm{N}<10)$, proveniente de algas, e a com estrutura celulósica $(\mathrm{C} / \mathrm{N}>12)$, produzida pelas plantas terrestres (Meyers 1994).

Para a análise de carbono orgânico total (COT), nitrogênio total $(\mathrm{NT}), \delta^{13} \mathrm{C}$ e $\delta^{15} \mathrm{~N}$, foi necessária a remoção física das conchas, raízes, folhas e demais fragmentos vegetais presentes nas amostras. Estas foram lavadas com água deionizada, secas em estufa a $50{ }^{\circ} \mathrm{C}$ e homogeneizadas. As amostras foram pesadas em cápsulas de estanho, seladas e enviadas posteriormente para o Laboratório de Isótopos Estáveis do CENA-USP. Foram utilizadas massas entre 1 e 50 mg para análises de $\mathrm{C}$ e entre 50 e $80 \mathrm{mg}$ para análise de $\mathrm{N}$. O equipamento utilizado foi um analisador elementar acoplado a um espectrômetro de massas ANCA SL2020. Os valores de COT e NT foram expressos em porcentagem por peso seco, enquanto que os valores isotópicos de $\delta^{13} \mathrm{C}$ e $\delta^{15} \mathrm{~N}$ em per mil (\%) foram calculados de acordo com os padrões internacionais VPDB para ${ }^{13} \mathrm{C}$ e $\mathrm{N}_{2}$ atmosférico para o ${ }^{15} \mathrm{~N}$, com precisão de $0,2 \%$. A partir dos resultados elementares, $\mathrm{C} / \mathrm{N}$ foi calculada para cada amostra sedimentar.

\subsection{Datação ${ }^{14} \mathrm{C}$}

Cinco amostras orgânicas in natura foram submetidas à remoção manual de contaminantes (e.g. fragmentos vegetais, insetos, conchas carbonáticas, dentre outros), tratadas com $\mathrm{HCl} 4 \%$ durante 4 horas a $60{ }^{\circ} \mathrm{C}$ para a remoção dos carbonatos, ácidos fúlvicos e resina. Após sucessivas lavagens até o $\mathrm{pH}$ se tornar neutro, as amostras foram secas em estufa a $50{ }^{\circ} \mathrm{C}$ e submetidas à combustão $\left(600-700^{\circ} \mathrm{C}\right)$ para a obtenção de $\mathrm{CO}_{2}$. As conchas foram lavadas com $\mathrm{HCl} 2 \%$, secas em estufa a $50{ }^{\circ} \mathrm{C}$, pulverizadas e encaminhadas para a linha da síntese de benzeno do Laboratório ${ }^{14} \mathrm{C}$ do CENA-USP para a obtenção do $\mathrm{CO}_{2}$. As cápsulas contendo o $\mathrm{CO}_{2}$ de todas as amostras, orgânicas e inorgânicas, foram enviadas para os Laboratórios 
UGAMS da Universidade da Geórgia (EUA) e LACUFF da Universidade Federal Fluminense (RJ - Brasil) para as datações por AMS - Accelerator Mass Spectrometry. As idades obtidas são expressas como anos AP (Antes do Presente) e em anos cal AP (anos calibrados Antes do Presente) com precisão de $\pm 2 \sigma$ (Reimer et al. 2009). As médias das idades calibradas foram usadas ao longo do texto.

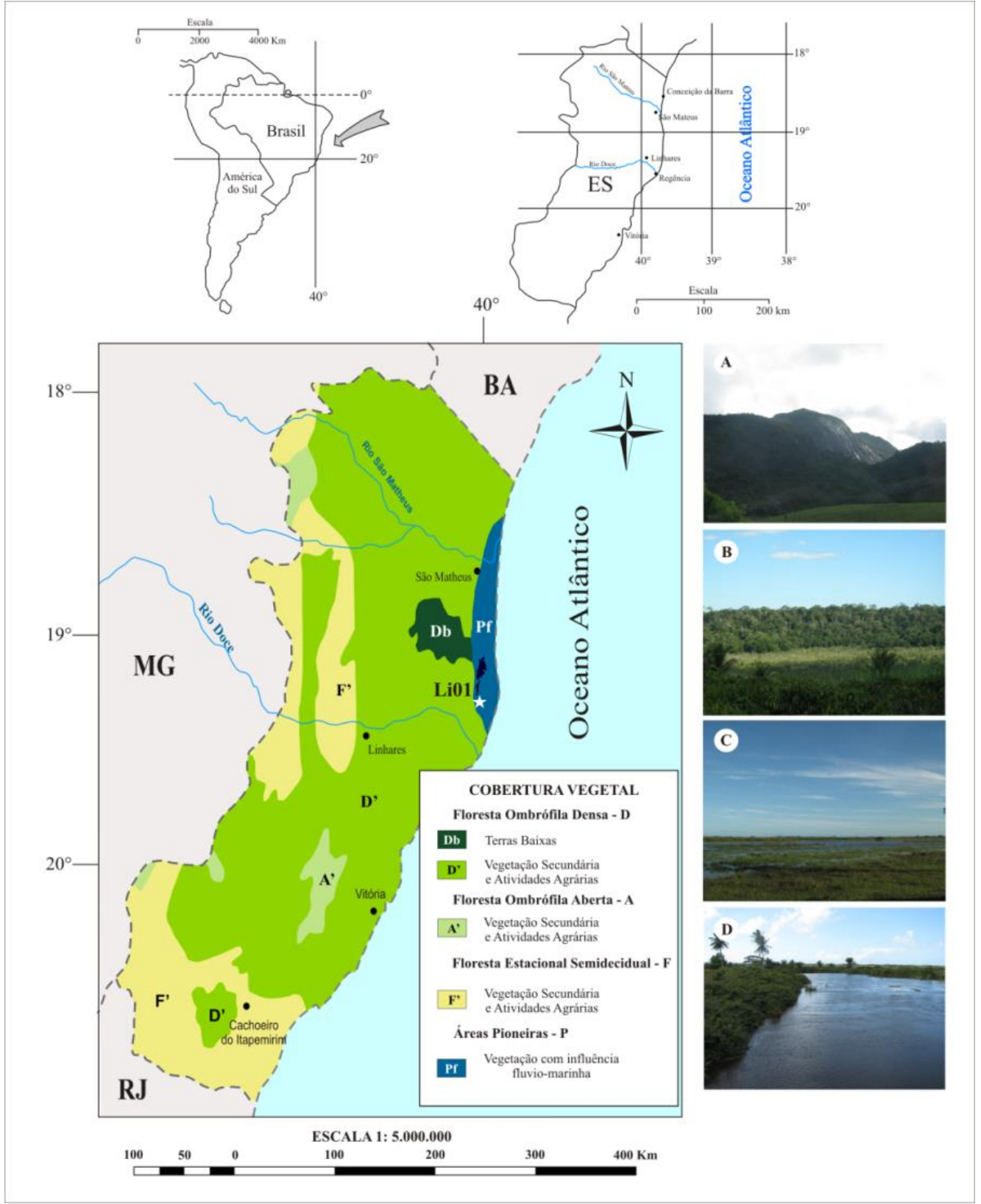

Figura 1: Mapa da cobertura vegetal do estado do Espírito Santo (modificado de IBGE, 2004), com a localização do local amostrado (Li01). A. Região Serrana (Pré-Cambriano). B. Planície de Tabuleiros (Neógeno). C. Planície costeira (Quaternário). D. Lagoa Bonita.

\subsection{Extração e análise de fitólitos}

Para a extração dos fitólitos a partir dos sedimentos, 102 amostras de $1 \mathrm{~cm}^{3}$ cada foram quimicamente tratadas com $\mathrm{H}_{2} \mathrm{O}_{2} 30 \%$ a $100{ }^{\circ} \mathrm{C}$ para a oxidação da matéria orgânica e com $\mathrm{HCl} 10 \%$ para a eliminação da fração carbonática. As lavagens das amostras foram realizadas por decantação e até o $\mathrm{pH}$ se tornar neutro. A partir do resíduo obtido, as lâminas foram montadas usando-se o Naphrax (índice de refração $=1,7$ ) como meio de montagem e encontram-se depositadas no Laboratório ${ }^{14} \mathrm{C}$ do CENA-USP.

Os fitólitos foram identificados e classificados de acordo com suas características morfológicas, seguindo o Código Internacional de Nomenclatura de Fitólitos (Madella et al. 2005), e adotou-se a permanência da nomenclatura dos morfotipos em inglês como forma de padronização. Foi estabelecida a contagem de 200 a 300 morfotipos com significado paleoambiental por amostra. Amostras em que este total não pôde ser obtido foram consideradas estéreis.

Os morfotipos foram agrupados em fitólitos de Poaceae, Arecaceae, Cyperaceae e dicotiledôneas, de acordo com bibliografia especializada (Twiss et al. 1969, Piperno 1988, Rapp Jr. \& Mulholland 1992, Fredlund \& Tieszen 1994, Alexandre et al. 1997), sendo que os indeterminados não foram adicionados na soma total. Quando possível, os morfotipos presentes 
na família Poaceae foram subdivididos em subfamílias, tais como Pooideae $\left(\mathrm{C}_{3}\right)$, Panicoideae $\left(\mathrm{C}_{4}\right)$ e Chloridoideae $\left(\mathrm{C}_{4} / \mathrm{C}_{3}\right)$. $\mathrm{A}$ análise quantitativa foi realizada em microscopia óptica de luz branca transmitida sob o aumento de 630x e as microfotografias obtidas sob o aumento de 1000x. Os diagramas de porcentagem e a análise de agrupamentos por similaridade, utilizada na interpretação paleoambiental, foram obtidos através dos programas Tilia, TiliaGraph e CONISS (Grimm 1987). A análise de componentes principais (PCA - Principal Components Analysis) foi obtida através do programa PAST (Hammer et al. 2001).

A partir dos resultados obtidos da análise quantitativa, foram calculados os seguintes índices para a interpretação das assembléias fitolíticas:

1. Índice de densidade arbórea - D/P (Alexandre et al. 1997, 1999, Barboni et al. 1999). A relação D/P reflete a razão entre o número de fitólitos de dicotiledôneas ( $\mathrm{D}=$ Globular granulate e/ou Globular rugose) pelo número de fitólitos de Poaceae $(\mathrm{P}=$ Bilobate, Cross, Saddle, Acicular hair, Trapeziform, Trapeziform short cell, Polylobate e Rondel). Valores elevados da razão D/P podem indicar o predomínio de elementos arbóreos, refletindo uma vegetação florestal. Dessa forma, valores baixos da razão D/P indicariam o predomínio de gramíneas e consequentemente uma vegetação predominantemente herbácea. Estudos prévios na África (e.g. Alexandre et al. 1997, 1999, Barboni et al. 1999) registraram valores superiores a 150 para Floresta Equatorial, entre 7 e 10 para Floresta Subcaducifólia e < 1 para savanas. Valores menores que 1 também podem refletir vegetação ripária $(0,7)$, vegetação de canais fluviais $(0,2)$ e estepes $(0,1)$. No Brasil, resultados recentes têm apontado valores de D/P de 0,2 para a Floresta Ombrófila Densa, 0,05 para o Cerrado Strictu sensu, e de 0,05 a 10 para a Floresta Ombrófila Mista (Calegari 2008, Calegari et al. 2013, Raitz 2012). Valores menores que 0,008 foram registrados para as zonas de campos do sul do Brasil (Raitz 2012).

2. Índice de adaptação à aridez - Iph (Diester-Haas et al. 1973, Alexandre et al. 1997). Este índice indica a proporção de fitólitos de gramíneas $\mathrm{C}_{4}$ adaptadas a condições de maior (Panicoideae) e de menor umidade (Chloridoideae). O índice é calculado a partir da equação Iph $(\%)=[$ Saddlel $($ Saddle + Cross + Bilobate) $\mathrm{x}$ 100, onde o Iph $>20-40 \%$ caracteriza formações de gramíneas dominadas por Chloridoideae, em condições quentes e secas, e o Iph <20-40\% caracteriza as associações sob clima quente e úmido, ou ainda devido à presença de umidade no solo.

3. Índice climático - Ic (Twiss 1987, 1992). É usado para determinar a abundância relativa de gramíneas $\mathrm{C}_{3}$ e $\mathrm{C}_{4}$, além de indicar a adaptação da formação vegetal a uma temperatura mínima e/ou à pressão parcial de dióxido de carbono $\left(\mathrm{pCO}_{2}\right)$. Este índice é calculado pela equação Ic $(\%)=[($ Rondel + Trapeziform polylobate + Trapeziform sinuate + Trapeziform)/ (Rondel + Trapeziform polylobate + Trapeziform sinuate + Trapeziform + Saddle + Cross + Bilobate $)] \mathrm{x}$ 100 , sendo que valores de Ic $>70 \%$ indicam domínio de
Pooideae $-\mathrm{C}_{3}$, enquanto valores $<30 \%$ indicam predomínio de gramíneas $\mathrm{C}_{4}$. As aplicações no Brasil desse índice têm obtido valores em torno de $16 \%$ para a Floresta Tropical Perenifólia, 20\% para o Cerrado Strictu sensu, e entre $25 \%$ e $60 \%$ para a Floresta Ombrófila Mista (Calegari 2008, Calegari et al. 2013, Raitz 2012).

4. Índice de estresse hídrico - Bi (Fs) (Bremond et al. 2005). É calculado a partir da porcentagem dos fitólitos do tipo Cuneiform bulliform em relação à soma de fitólitos de gramíneas, através da equação Bi $(\%)=$ Cuneiform bulliform / [(short cells + acicular + Cuneiform bulliform)] x 100. Altos valores do índice Bi podem indicar estresse hídrico local ou alta taxa de transpiração, acarretando na alta produção de fitólitos buliformes pelos tecidos vegetais. No Brasil, valores de $\mathrm{Bi}$ entre $11 \%$ e $81 \%$ foram registrados para áreas costeiras do estado do Rio de Janeiro (Coe et al. 2013, 2014a).

\section{Resultados e discussão}

\subsection{Datação ${ }^{14} \mathrm{C}$}

Os resultados das datações das amostras de sedimento são apresentados na tabela 1. A amostra mais basal do testemunho (11,70-11,62 m) foi datada em $\sim 47260$ anos cal AP, e as médias das idades calibradas para as outras amostras foram de $\sim 35195$ anos cal AP (8,86-8,80 m), 38058 anos cal AP (6,30$6,20 \mathrm{~m}), \sim 29452$ anos cal AP $(3,75-3,70 \mathrm{~m}), \sim 7589$ anos cal AP (1,75-1,65 m) e $\sim 142$ anos cal AP (0,3-0,4 $\mathrm{m})$. De acordo com os resultados obtidos, foram observadas inversões nas idades das amostras datadas no intervalo entre 8,8 e 6,2 metros do testemunho. Esta inversão pode ser atribuída ao conteúdo do material datado, uma vez que a matéria orgânica sedimentar e conchas foram datadas nas profundidades de $8,8 \mathrm{~m}$ e 6,2 metros, respectivamente. Geralmente, a matéria orgânica encontrada em sedimentos marinhos é apropriada para a datação por ${ }^{14} \mathrm{C}$, assumindo uma relação temporal entre o material datado e o momento da sedimentação. Entretanto, é possível que a precipitação posterior de calcita sobre as conchas de moluscos tenha incorporado carbono antigo de sedimentos carbonáticos. Esse processo pode causar um envelhecimento nas idades ${ }^{14} \mathrm{C}$ de até 3000 anos (Rubin et al. 1963, Evin et al. 1980, Goodfriend 1987, Goodfriend \& Stipp 1983, Pigati et al. 2013).

Da mesma forma, a datação da matéria orgânica pode ter sido influenciada devido à sedimentação do Rio Doce, já que o material foi coletado na área deltaica. Segundo Stanley \& Hait (2000), a maioria das idades estabelecidas por ${ }^{14} \mathrm{C}$ em regiões de deltas apresentam inversões e são mais antigas do que o esperado. Ainda segundo estes autores, as idades anômalas em deltas são em parte respostas do efeito reservatório e introdução de carbono mais antigo, bem como a influência do aporte e deposição de sedimentos em sequências fluviais e deltaicas. Em adição às hipóteses mencionadas na justificativa das inversões de idade, importante mencionar que a técnica AMS necessita de apenas miligramas de material para se efetuar a datação 
Estudos ambientais sobre a vegetação e o clima no Holoceno

${ }^{14} \mathrm{C}$, o que aumenta consideravelmente as chances da incorporação de materiais mais jovens ou antigos à amostra (sedimento, solo, etc.) a ser analisada, dependendo das características ambientais do local de amostragem.

Tabela 1: Datações ${ }^{14} \mathrm{C}$ de amostras sedimentares do testemunho Li01.

\begin{tabular}{|c|c|c|c|c|c|}
\hline $\begin{array}{l}\text { Número do } \\
\text { laboratório }\end{array}$ & $\begin{array}{l}\text { Profundidade } \\
(\mathrm{m})\end{array}$ & $\begin{array}{l}\text { Tipo de } \\
\text { amostra }\end{array}$ & Idade $(\operatorname{anos}$ AP) & $\begin{array}{l}\text { Idade calibrada } \\
\text { (anos cal AP) }\end{array}$ & $\begin{array}{c}\text { Média da idade calibrada } \\
\text { (anos cal AP) }\end{array}$ \\
\hline UGAMS15847 & $0,4-0,3$ & Sedimento & $140 \pm 25$ & $7-280$ & $\sim 143$ \\
\hline UGAMS10565 & $1,75-1,65$ & Sedimento & $6710 \pm 30$ & $7556-7622$ & $\sim 7589$ \\
\hline UGAMS10566 & $3,75-3,70$ & Sedimento & $24610 \pm 70$ & $29226-29678$ & $\sim 29452$ \\
\hline LACUFF13018 & $6,30-6,20$ & Conchas & $33358 \pm 948$ & $36102-40014$ & $\sim 38058$ \\
\hline UGAMS11693 & $8,86-8,80$ & Sedimento & $31220 \pm 100$ & $34873-35518$ & $\sim 35195$ \\
\hline LACUFF12038 & $11,70-11,62$ & Sedimento & $44232 \pm 812$ & $45460-49060$ & $\sim 47260$ \\
\hline
\end{tabular}

UGAMS - Universidade da Geórgia, EUA; LACUFF - Universidade Federal Fluminense, Brasil.

\subsection{Estratigrafia}

O perfil sedimentar Li01 constitui-se, em geral, de fácies com areias grossas a finas, maciças ou com estratificações plano-paralelas ou cruzadas, e argilas, maciças ou laminadas, intercaladas por depósitos heterolíticos (figura 2). As sucessões apresentam padrão granocrescente e/ou granodecrescente ascendente.

Os depósitos de areia foram descritos como fácies de areia maciça, areia com laminação plano-paralela e areia com estratificação cruzada. As fácies de areia maciça apresentam sedimentos de granulometria areia média a muito fina, maciça, grãos bem selecionados, de cor amarelo e marrom, podendo apresentar sinais de bioturbação, restos de conchas e deformação sedimentar. Os depósitos de areia com laminação plano-paralela são constituídos por sedimentos de granulometria areia grossa a muito fina, micácea, bem selecionados, e de cor amarelo a marrom. E por fim, as fácies de areia com estratificação cruzada apresentam sedimentos de granulometria areia grossa a fina, bem selecionados, de cor amarelo a marrom, podendo apresentar areia quartzosa ou com grande quantidade de muscovita, e localmente clastos de argila.

As fácies de argila maciça apresentam sedimentos de granulometria argila, de cor cinza a cinza esverdeado, endurecida ou plástica, com ocorrência de conchas fósseis diversas. Esta fácies é semelhante á fácies de pelito maciço, que se constitui por material argiloso (silte e argila), de coloração cinza esverdeado e com ocorrência de material conchífero fóssil. Ao longo do testemunho também ocorrem fácies de argila laminada, com coloração cinza esverdeada, plástica, podendo apresentar gradações para depósitos heterolíticos lenticulares.

Os depósitos heterolíticos foram descritos como flaser, lenticular/streaky e wavy, que se constituem, basicamente, por sedimentos intercalados de granulometria argila e areia, indicando alternância na energia do fluxo durante a deposição. A fácies de depósito heterolítico flaser corresponde a sedimentos de areia muito fina a média, bem selecionada, com lâminas de argila descontínuas sob forma de canaletas. $\mathrm{O}$ depósito heterolítico lenticular/streaky do testemunho é caracterizado pela ocorrência de argila cinza, plástica, com lentes de areia, podendo apresentar localmente estratificação cruzada. E no depósito heterolítico wavy camadas de argila cinza se alternam com camadas de areia de cor amarela.

\subsection{Análise elementar e isotópica de $\mathrm{C}$ e $\mathrm{N}$ (COT, NT, $\delta^{13} \mathrm{C}$ e $\left.\delta^{15} \mathrm{~N}\right)$}

A concentração de COT do testemunho Li01 variou de $0,16 \%(2,8 \mathrm{~m})$ a $3,28 \%(11,8 \mathrm{~m})$ ao longo do perfil, enquanto os valores de NT obtidos foram registrados entre $0,01 \%(1,4 \mathrm{~m} ; 1,6 \mathrm{~m} ; 11,2 \mathrm{~m} ; 11,3 \mathrm{~m})$ e $0,09 \%$ $(4,5 \mathrm{~m})$. Os valores de $\delta^{13} \mathrm{C}$ variaram de $-4,25 \%$ o $(7,3$ $\mathrm{m} ; 8,2 \mathrm{~m})$ a $-28,06 \%$ o $(3,7 \mathrm{~m})$, e os valores de $\delta^{15} \mathrm{~N}$ variaram de $-6,16 \%$ o $(2,4 \mathrm{~m} ; 3,5 \mathrm{~m})$ a $15,75 \%$ o $(3,9 \mathrm{~m})$. $\mathrm{C} / \mathrm{N}$ indicou valores entre $7,8(2,3 \mathrm{~m})$ e $99(11,6 \mathrm{~m})$. Em linhas gerais, os resultados isotópicos e elementares indicaram que a matéria orgânica sedimentar foi originada a partir de fitoplâncton, com possível influência marinha, e por plantas $C_{3}$ e $C_{4}$ (Meyers 1997). Os resultados isotópicos e elementares encontram-se na figura 2.

\subsection{Análise de fitólitos e interpretação paleoambiental}

Alguns dos principais morfotipos de fitólitos identificados são apresentados na figura 3. A partir da caracterização das assembléias de fitólitos e dos agrupamentos estatísticos gerados por similaridade, foi possível o estabelecimento de três intervalos (figura 4) que refletem as mudanças na vegetação ao longo do Holoceno na área estudada.

Embora 102 amostras ao longo do perfil sedimentar tenham sido processadas para a análise de fitólitos, estes bioindicadores foram recuperados em 14 amostras correspondentes aos $150 \mathrm{~cm}$ superiores do testemunho com idades $<\sim 7600$ anos. As demais amostras apresentaram-se estéreis e não puderam ser utilizadas na interpretação paleoambiental. De acordo com Cohen et al. (2014), as associações de fácies sedimentares entre $12 \mathrm{~m}$ e $1,8 \mathrm{~m}$ foram interpretadas como sendo fácies de um sistema deltaico. As mudanças no nível relativo do mar, observadas pelos autores para a região durante o Pleistoceno Tardio e o Holoceno, podem ter influenciado na preservação dos fitólitos, uma vez que a preservação destes bioindicadores depende amplamente das características físicas e químicas do ambiente deposicional (Piperno 2006).

Através da análise de componentes principais (figura 5), foi possível observar que o eixo 1 define-se por valores positivos de Globular granulate e Globular 
echinate, enquanto que os morfotipos Cuneiform bulliform, Parallepipedal bulliform e Elongate psilate apresentaram valores negativos. Este eixo pode ser considerado como um indicador de densidade arbórea, uma vez que os fitólitos definidos por valores positivos são característicos de dicotiledôneas arbóreas ( $G$. granulate) e palmeiras (G. echinate). Os fitólitos com valores negativos são aqueles produzidos por todas as subfamílias de gramíneas, consequentemente refletindo baixa densidade arbórea.

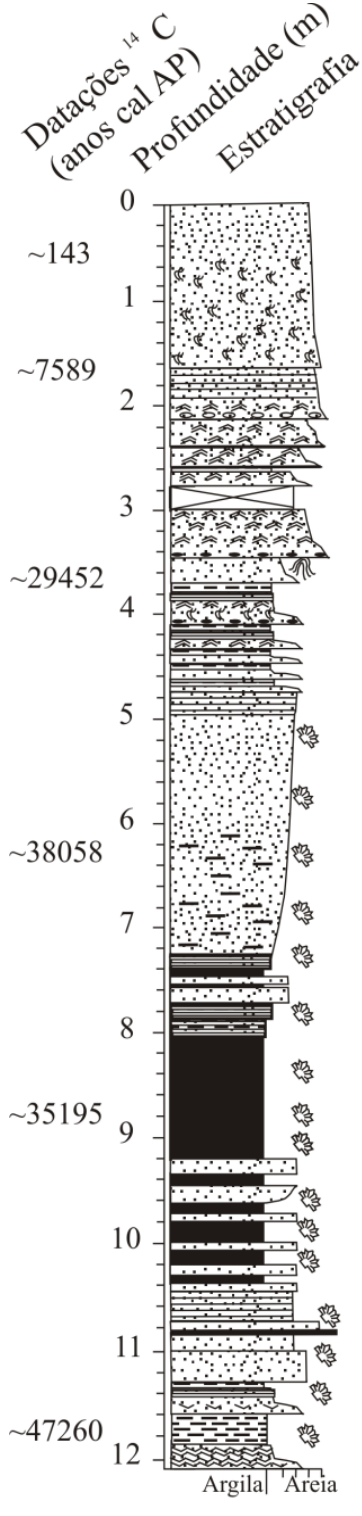

LEGENDA
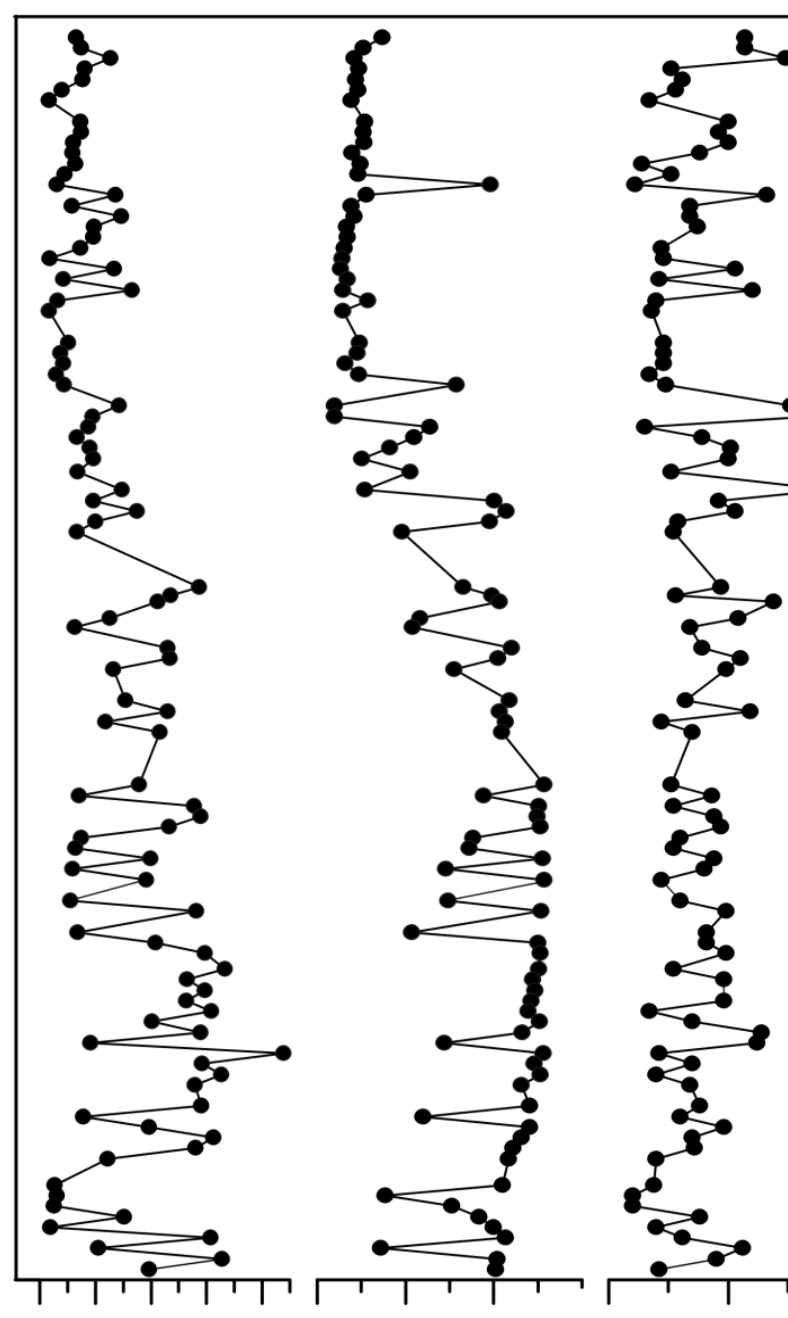

2
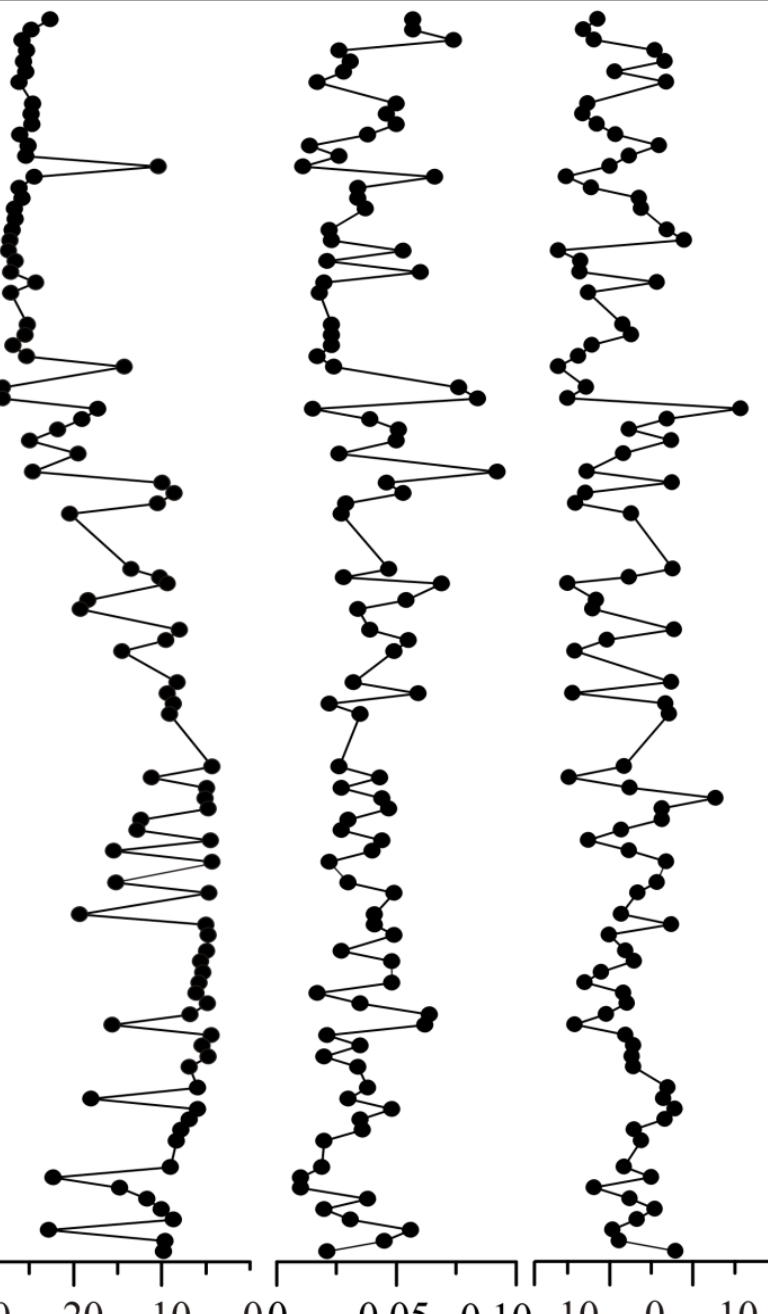

$\begin{array}{lllllll}0 & 1 & 2 & 3 & 4 & -30\end{array}$

$-20-10$

00

$0,05 \quad 0,10-10$

N-total $(\%)$

$\delta^{15} \mathrm{~N}(\%)$

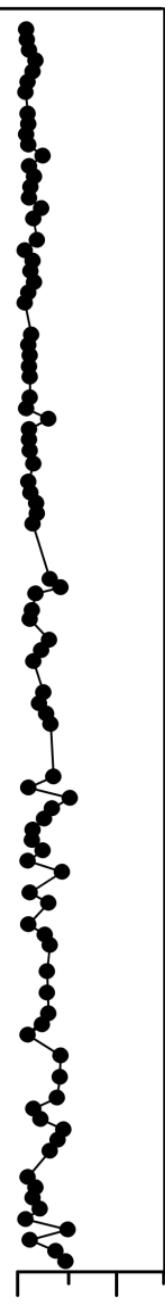

$0 \quad 200$

$\operatorname{COT}(\%) \quad \delta^{13} \mathrm{C}(\%)$
Areia maciça

Pelito maciço

Argila maciça

Argila com laminação paralela

Areia bioturbada
凡 Deformação sedimentar

- Clasto de argila

Clasto de argila

$\approx$ Fragmento vegetal

ᄉ Raízes

Figura 2: Estratigrafia, Idades ${ }^{14} \mathrm{C}$ e valores de carbono orgânico total $(\mathrm{COT}), \delta^{13} \mathrm{C}$, nitrogênio total (N-total), $\delta^{15} \mathrm{~N}$ e C/N do perfil Li01.

O eixo 2 foi definido pelos morfotipos Cuneiform bulliform, Parallepipedal bulliform e Elongate psilate para valores positivos, e Bilobate para valores negativos. Este eixo pode indicar estresse hídrico, uma vez que quanto mais a planta transpira e/ou sofre estresse hídrico, mais células buliformes são produzidas. Da mesma forma, o morfotipo Bilobate é preferencialmente produzido por gramíneas Panicoideae- $\mathrm{C}_{4}$, que crescem em áreas quentes e com disponibilidade de água no solo (Bremond et al. 2005). Intervalo $1(150 \mathrm{~cm}$ a $95 \mathrm{~cm} ; \sim 7589$ anos cal AP a -5441 anos cal AP - Idade interpolada) 
O intervalo 1 é caracterizado pelo predomínio de fitólitos de dicotiledôneas $( \pm 50,4 \%)$, seguido pelos fitólitos de Poaceae $( \pm 35,5 \%)$ e de Areaceace $( \pm 13 \%)$. Dentre o conjunto fitolítico referente às gramíneas, os morfotipos Parallepipedal bulliform ( \pm 16,9\%), Elongate psilate $( \pm 5,2 \%)$ e Cuneiform bulliform $( \pm$ $4,7 \%$ ) foram predominantes. Os morfotipos Bilobate e Trapeziform foram registrados com média de $2 \%$, enquanto os morfotipos Trapeziform sinuate e Rondel apareceram com média aproximadamente de $1 \%$. Os demais morfotipos estiveram infrarepresentados ou apareceram pontualmente. Fitólitos característicos da família Cyperaceae não foram registrados neste intervalo.

Os valores do índice Ic variaram de $44 \%(120 \mathrm{~cm})$ a $88 \%(150 \mathrm{~cm})$. De acordo com estudos realizados na América do Norte, foi proposto que valores maiores que $70 \%$ indicam predomínio de gramíneas Pooideae$\mathrm{C}_{3}$, enquanto que valores menores que $30 \%$ indicam predomínio de gramíneas $\mathrm{C}_{4}$ (Twiss 1992, Fredlund \& Tieszen 1994). Embora estes valores tenham sido estabelecidos para as pradarias norte americanas, a comparação com os resultados obtidos neste intervalo mostra uma tendência de que a vegetação durante o Holoceno Inferior era composta por uma mistura entre gramíneas $\mathrm{C}_{3}$ e $\mathrm{C}_{4}$.

Os valores de Iph foram calculados apenas para duas amostras devido à ausência do morfotipo Saddle nas outras amostras sedimentares do intervalo, sendo que os valores obtidos foram de 4,5\% (140 cm) e 6,6\% $(120 \mathrm{~cm})$. Segundo Bremond et al. (2005), valores de Iph menores que $20-40 \%$ indicam associações em que gramíneas Panicoideae são dominantes, sugerindo clima quente e úmido e/ou maior disponibilidade de umidade no solo. A razão D/P variou de 3,9 $(150 \mathrm{~cm})$ a
9,7 $(110 \mathrm{~cm})$, refletindo o predomínio de vegetação arbórea na região, sendo também comparados com os valores de D/P maiores que 5 encontrados em amostras de Floresta Ombrófila na África (Alexandre et al. 1997, Bremond et al. 2005). No Brasil esse índice ainda carece de calibração, pois os valores obtidos para áreas de Floresta Ombrófila Densa, Floresta Ombrófila Mista e Cerrado (Calegari 2008, Raitz 2012) têm sido menores comparados aos do continente africano.

Em um estudo palinológico realizado na Lagoa do Macuco, distante aproximadamente em $17 \mathrm{~km}$ do local analisado neste trabalho, Buso Junior et al. (2013a) registraram alta porcentagem de grãos de pólen de táxons arbóreos para o intervalo de tempo entre 7623 e 4396 anos cal AP. Segundo os autores, a assembléia polínica, composta principalmente por Urticaceae/Moraceae, Fabaceae e Alchornea spp., estaria refletindo a presença da floresta tropical durante o Holoceno Inferior, além de clima úmido, fato evidenciado pela alta frequência de esporos de Cyatheaceae e grãos de pólen de Arecaceae. Altos valores percentuais do morfotipo Globular echinate $( \pm$ 13\%), típico da família Arecaceae, também foram registrados entre 7589 anos cal AP e $~ 5441$ anos cal AP (idade interpolada) para o testemunho aqui analisado. Segundo Buso Junior et al. (2013a), uma possível explicação para os altos níveis de umidade na região seria a intensificação do sistema de monções da América do Sul devido à migração da Zona de Convergência Intertropical (ZCIT) para o Sul (Ledru et al. 1998), resultando no aumento da precipitação de verão e na umidade mantida pelas massas de ar polar durante o inverno.
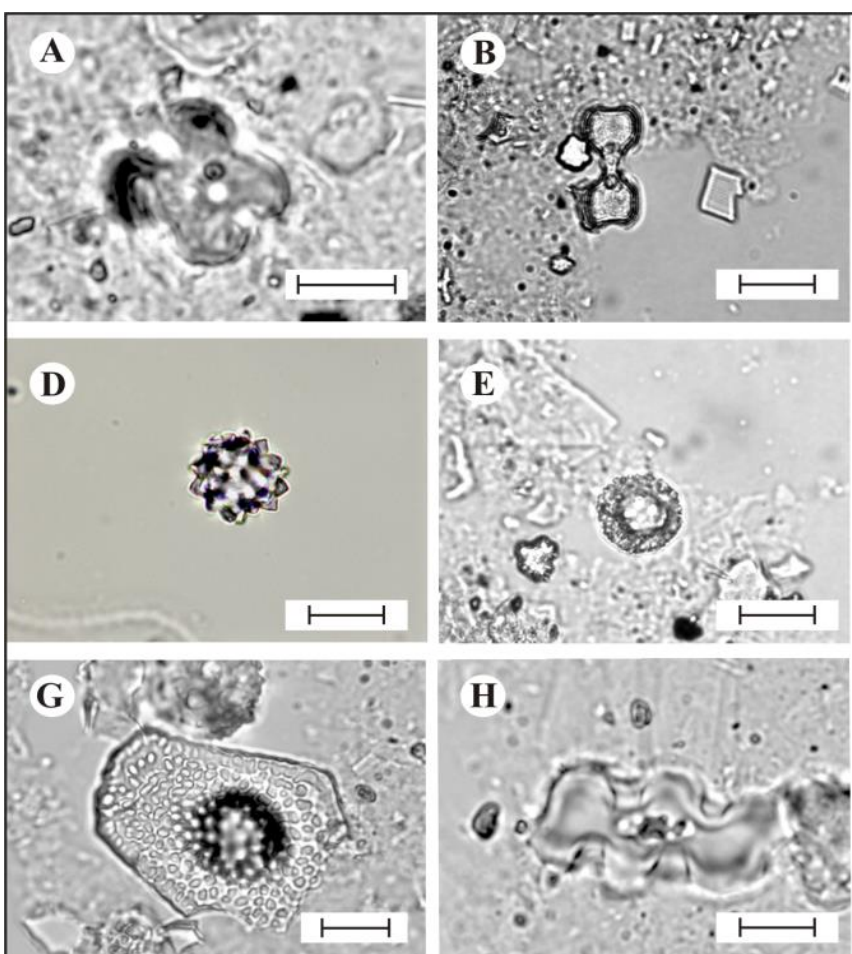
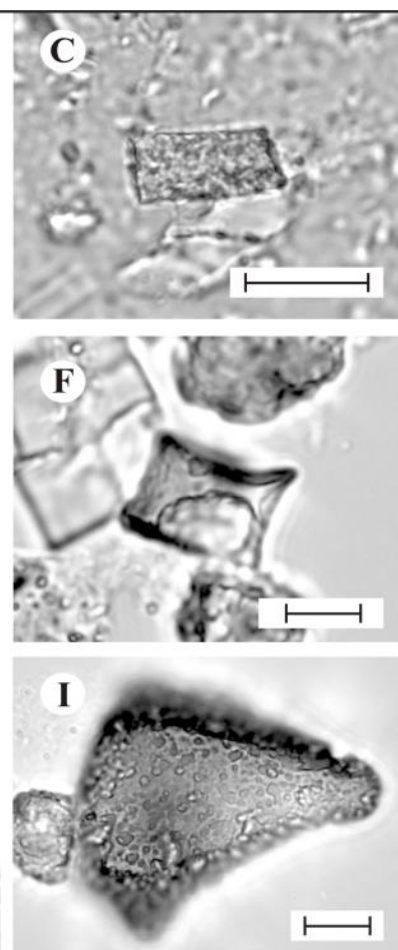

Figura 3: Alguns dos principais morfotipos de fitólitos identificados no perfil Li01. A. Cross. B. Bilobate. C. Parallepipedal bulliform. D. Globular echinate. E. Globular granulate. F. Trapeziform. G. Papillae. H. Trapeziform polylobate. I. Cuneiform bulliform. Microfotografias obtidas em aumento de 1000x. Escala: $10 \mu \mathrm{m}$. 


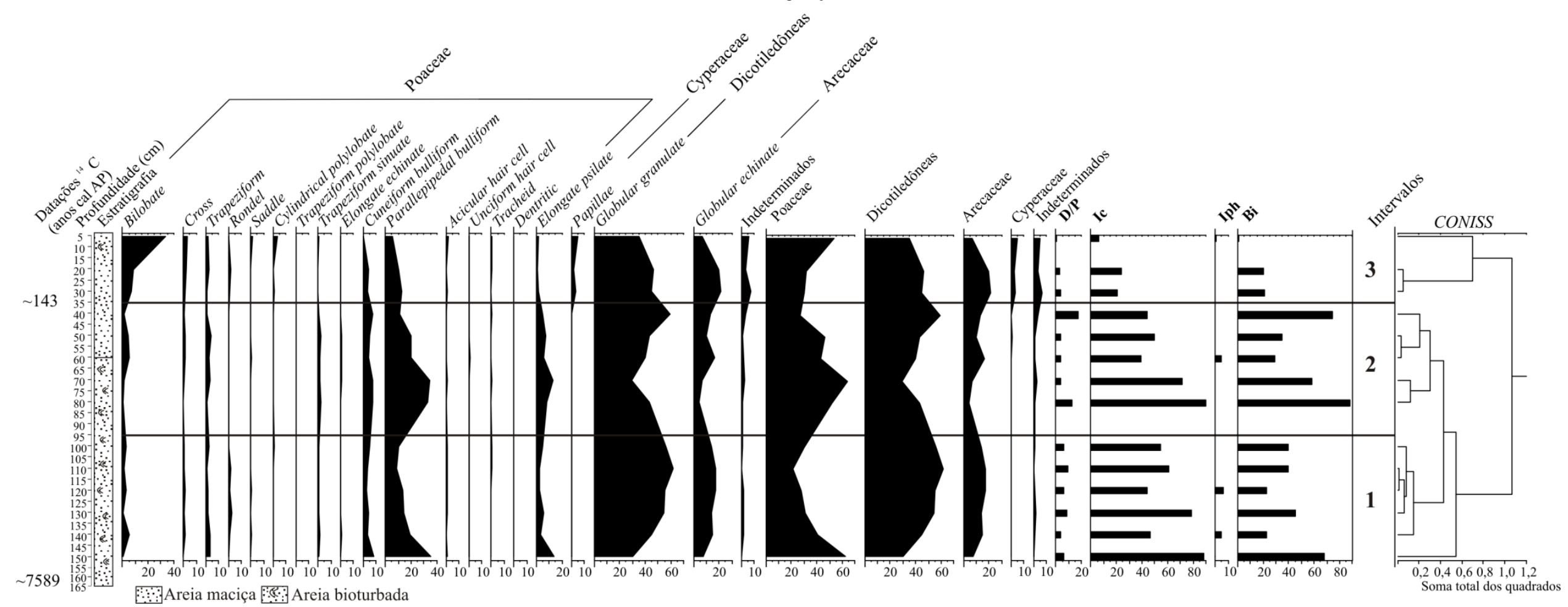

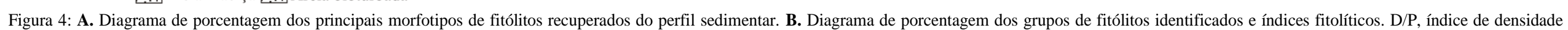
arbórea. Ic, índice climático. Iph, índice de aridez. Bi, índice de estresse hídrico. 


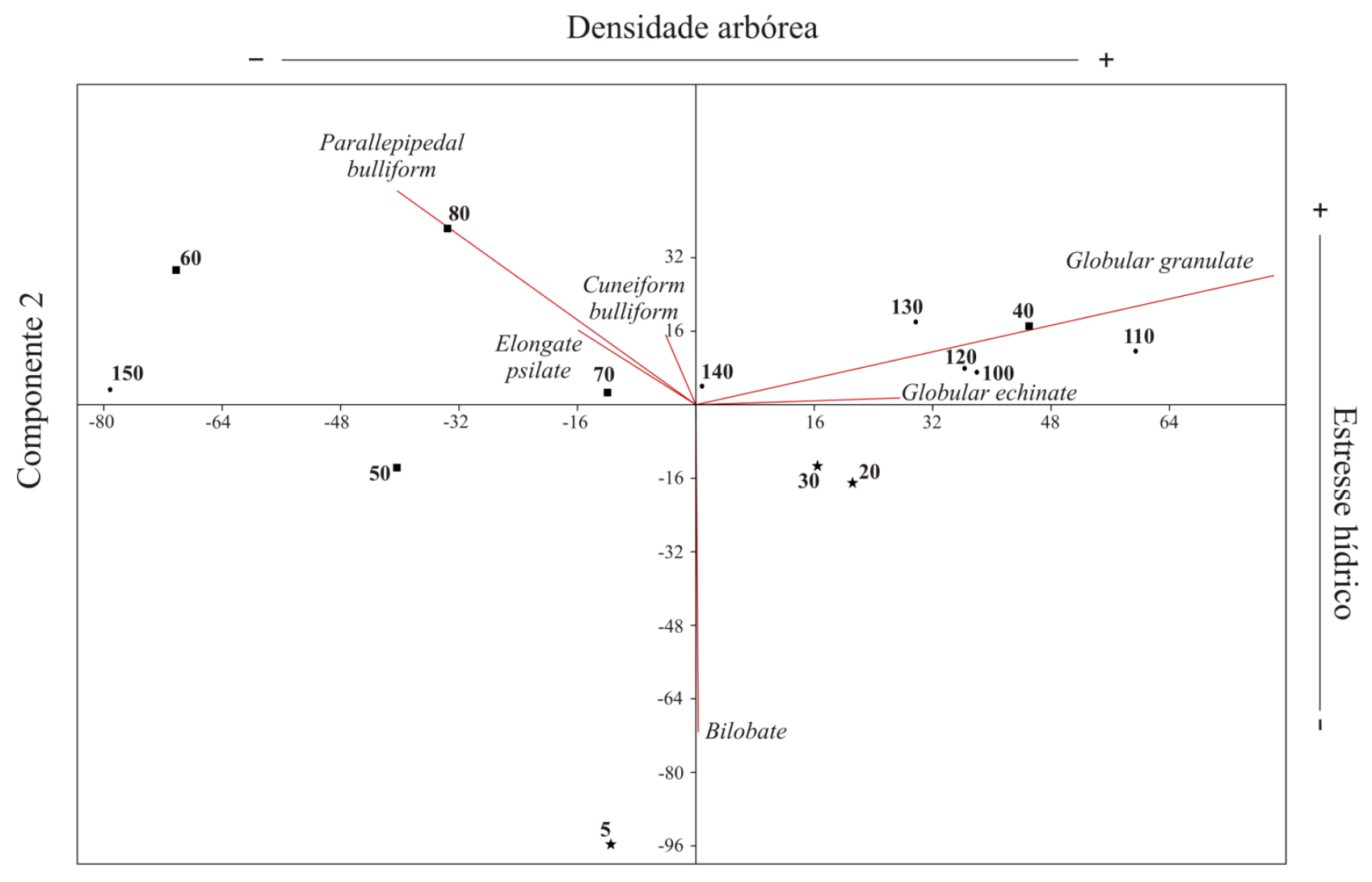

Componente 1

Figura 5: Análise de componentes principais para os morfotipos de fitólitos do perfil sedimentar Li01. Os círculos indicam as amostras agrupadas do intervalo 3, os quadrados para as amostras do intervalo $2 \mathrm{e}$ as estrelas para as amostras do intervalo 1 .

Em outro trabalho na região norte do estado do Espírito Santo, Nascimento (2012) realizou análise palinológica de um testemunho lacustre próximo ao município de Linhares, e verificou o predomínio de elementos arbóreos e arbustivos de Floresta Ombrófila Densa entre 7320 e 5818 anos cal AP. Segundo o autor, grãos de pólen de Hedyosmun spp., Ilex spp., Myrsine spp., Lamanonia spp., Symplocos spp. e Myrtaceae durante este intervalo de tempo sugerem a presença de uma floresta fria e úmida. No entanto, apenas os valores de Ic de $88 \%(150 \mathrm{~cm})$ e $78,9 \%(130 \mathrm{~cm})$ indicam o predomínio de gramíneas Pooideae- $\mathrm{C}_{3}$, que são indicativas de locais úmidos e frios ou ainda de altas altitudes (Fredlund \& Tieszen 1994). Nas demais amostras do intervalo não foram registrados indícios de que as condições climáticas eram mais frias do que as atuais.

Para o índice $\mathrm{Bi}$, os valores encontrados variaram de $23 \%(140 \mathrm{~cm} ; 120 \mathrm{~cm})$ a $68 \%(150 \mathrm{~cm})$. Embora trabalhos de interpretação paleoambiental que utilizaram dados do índice Bi para fins de comparação sejam escassos, principalmente no Brasil (e.g. Coe et al. 2013, 2014a,b,c), os valores registrados podem estar indicando uma tendência de moderado estresse hídrico. No entanto, os outros índices fitolíticos calculados indicam clima úmido e a presença de umidade no solo. Sendo assim, a alta produção de fitólitos do tipo Cuneiform bulliform pelas plantas poderia ter sido ocasionada principalmente por estresse salino (Grigore et al. 2010), uma vez que a área é próxima da linha de costa atual.

Trabalhos realizados na costa norte do estado do Espírito Santo (e.g. Buso Junior et al. 2013b, França et al. 2013, Castro et al. 2013, Lorente et al. 2014) utilizando isótopos estáveis $(\mathrm{C}$ e $\mathrm{N})$ e bioindicadores, mostraram a presença de estuários e lagunas entre $\sim 8000$ e 3000 anos AP na região, como resultado do aumento do nível relativo marinho (Angulo et al. 2006). Ainda segundo esses autores, a litologia dos testemunhos sedimentares para o período era composta predominantemente por silte e argila, correspondendo assim a ambientes com características redutoras. Além disso, os autores também verificaram através de grãos de pólen a presença de densa cobertura vegetal com espécies de manguezal. No entanto, os sedimentos deste intervalo referentes ao Li01 são em sua maioria de granulometria grossa, além de que nenhum sinal fitolítico para espécies de manguezal (Das et al. 2014) foi identificado. Dessa forma, a vegetação da área de estudo deveria ocorrer no entorno dos manguezais, tais como atualmente ocorrem a restinga e a Floresta Ombrófila.

Em linhas gerais, os índices fitolíticos associados com os valores isotópicos de $\delta^{13} \mathrm{C}(-24 \%$ a $-26 \%$ ) e os valores percentuais de fitólitos de dicotiledôneas e Arecaceae neste intervalo mostram que a vegetação na área de estudo era composta pela mistura de árvores e gramíneas $\mathrm{C}_{3}$ e $\mathrm{C}_{4}$, com possível influência marinha, o que pode ser interpretado como sendo semelhante e/ou 
comparável à vegetação de restinga. Esse tipo de vegetação se desenvolve sob depósitos litorâneos arenosos originados pelo acúmulo de sedimentos provenientes do embasamento cristalino e da transgressão marinha no Quaternário (Suguio \& Martin 1990).

Intervalo 2 (95 a $35 \mathrm{~cm} ; \sim 5441$ anos cal AP - Idade interpolada a $\sim 143$ anos cal AP)

Para o intervalo 2 foi registrado o predomínio de fitólitos de Poaceae $( \pm 46 \%)$ e dicotiledôneas $( \pm 43 \%)$. Seguem os morfotipos Globular echinate ( $\pm 10 \%)$, típico de palmeiras da família Arecaceae, e Papillae $( \pm$ $0,2 \%$ ) que é característico da família Cyperaceae. Os fitólitos da família Cyperaceae aparecem pela primeira vez no registro sedimentar. Dentre o grupo Poaceae, os morfotipos Parallepipedal bulliform, Elongate psilate e Cuneiform bulliform continuam predominantes, com médias de $23,5 \%, 7,9 \%$ e $6,7 \%$, respectivamente. Fitólitos do tipo Bilobate $( \pm 2,3 \%)$, Trapeziform $( \pm$ $2,1 \%)$ e Trapeziform sinuate $( \pm 1,6 \%)$ aparecem como elementos subordinados. Os morfotipos Cross e Elongate echinate foram registrados com médias não excedendo a $1 \%$. Os demais morfotipos fitolíticos aparecem pontualmente.

Os valores do índice Ic variaram de $39 \%(60 \mathrm{~cm})$ a $90 \%(80 \mathrm{~cm})$, e foi possível calcular o índice Iph de 5\% apenas para a amostra a $60 \mathrm{~cm}$, devido à ausência do morfotipo Saddle nas outras amostras. Os valores destes índices são semelhantes aos registrados para o intervalo anterior, refletindo assim a presença de gramíneas $\mathrm{C}_{3}$ e $\mathrm{C}_{4}$ em ambiente úmido (Twiss 1992, Bremond et al. 2005). Os valores de $\delta^{13} \mathrm{C}$ apresentaram média de $-25 \%$, corroborando com os índices fitolíticos no que diz respeito à presença de plantas $\mathrm{C}_{3}$.

$\mathrm{O}$ índice de densidade arbórea $(\mathrm{D} / \mathrm{P})$ variou de 3,4 $(50 \mathrm{~cm})$ a $17,8(40 \mathrm{~cm})$. Os valores de $\mathrm{D} / \mathrm{P}$ das amostras entre $70 \mathrm{~cm}$ e $50 \mathrm{~cm}$ indicam uma tendência de que a vegetação arbórea se tornou menos densa do que no período anterior, uma vez que constatou-se o aumento nos valores percentuais de fitólitos de Poaceae. No entanto, os valores de D/P de 13 a $80 \mathrm{~cm} \mathrm{e}$ de 17,8 a $40 \mathrm{~cm}$ podem indicar um adensamento da vegetação na base e no topo do intervalo, refletindo uma vegetação em mosaico constituída por elementos arbóreos e herbáceos. Essa oscilação entre elementos arbóreos também foi observada por Nascimento (2012) para a Lagoa Juparanã (ES) entre 3000 e 2000 anos AP. É provável que a vegetação durante este intervalo fosse semelhante aquela interpretada para o intervalo anterior, sendo comparável a restinga.

No que tange às variações do índice $\mathrm{D} / \mathrm{P}$, não se exclui a possibilidade de que fontes alóctones tenham contribuído para a assembléia fitolítica. Meios de transporte e deposição de fitólitos, tais como processos eólicos e fluviais (Fredlund \& Tieszen 1994, Barboni et al. 1999), são atuantes em planícies costeiras, o que poderia ter resultado nos valores mais altos de D/P na base e no topo do intervalo, além do possível sinal fitolítico proveniente da Floresta Ombrófila Densa presente nas adjacências da área.

Para o índice $\mathrm{Bi}$ foram encontrados valores entre $29 \%(60 \mathrm{~cm})$ e $88 \%(80 \mathrm{~cm})$. Da mesma forma que o índice $\mathrm{D} / \mathrm{P}$, foi observado que os maiores valores de $\mathrm{Bi}$ registrados ao longo do testemunho ocorreram nas amostras da base e do topo do intervalo. A partir destes resultados, é possível inferir que houve períodos intercalados de maior e menor estresse hídrico para as plantas. Valores semelhantes de Bi foram encontrados por Coe et al. (2014a) ao longo de um perfil de solo datado em 6000 anos AP na bacia do Rio São João, região costeira do estado do Rio de Janeiro.

Segundo Castro et al. (2013), após 5000 anos AP, com a regressão marinha (Angulo et al. 2006), houve o desenvolvimento de cordões arenosos na região costeira do Espírito Santo através da dispersão de areias provenientes do delta do Rio Doce, resultando assim no deslocamento dos estuários. À medida que o estuário foi sendo fechado, a influência marinha foi sendo reduzida e o influxo de água doce aumentou nos depósitos sedimentares.

Com base na análise de palinofácies, Lorente et al. (2014) verificaram que durante o período de regressão marinha ( 4847 a $\sim 3800$ anos cal AP) houve um aumento de fitoclastos opacos, tecido vegetal oxidado, como resultado de possíveis períodos de alto influxo fluvial intercalados com períodos de seca. Com base nessa informação, é possível inferir que o índice Bi neste intervalo esteja não só refletindo o estresse salino durante o período de regressão, como também os períodos de estresse hídrico devido à sazonalidade estabelecida na região.

Entre 4396 e 1287 anos cal AP, Buso Junior et al. (2013a) interpretaram a presença de grãos de pólen de Symphonia spp., Macoubea spp., Ilex spp. e esporos de Salvinia spp. como associados ao processo de colonização do ambiente anteriormente inundado e sob influência marinha, e formação de um ambiente de planície de inundação. Segundo esses autores, após 4000 anos AP houve o estabelecimento do atual clima sazonal para o norte do estado do Espírito Santo, devido ao deslocamento da ZCIT para sua posição atual (Ledru et al. 1998). Como as massas de ar polar ficaram restritas nas latitudes a sul, o inverno em Linhares se tornou mais seco do que no Holoceno Inferior (Buso Junior et al. 2013a).

De maneira geral, a assembléia fitolítica e os dados de isótopos de $\delta^{13} \mathrm{C}$ sugerem que a vegetação que ocupava a área de estudo provavelmente pode ser associada a uma das fitofisionomias de restinga, da mesma forma que entre o período de $\sim 7589$ anos cal AP a 5441 anos AP (idade interpolada). No entanto, a vegetação ocupava uma área periodicamente alagada em condições de sazonalidade. De acordo com Pereira (1990), em uma área de Guarapari (ES), foram definidas doze formações para a restinga com diferente densidade arbórea e composição florística, incluindo floresta periodicamente inundada, mata seca, halófita, psamófila, pós-praia, dentre outras. Dessa forma, a assembléia fitolítica estaria indicando um mosaico entre diferentes formações da restinga, com elementos arbóreos e herbáceos.

Intervalo 3 (35 a $0 \mathrm{~cm}$; < 143 anos cal AP)

O intervalo 3 é caracterizado pelo predomínio de fitólitos de dicotiledôneas $( \pm 42 \%)$, seguido pelos 
fitólitos de Poaceae $( \pm 38 \%)$, Arecaceae $( \pm 16 \%)$ e Cyperaceae $( \pm 3,3 \%)$, sendo que este último apresentou os maiores valores percentuais de todo o perfil. Dentre os morfotipos de gramíneas, Bilobate apresentou os maiores valores percentuais, com média de $16,4 \%$. Parallepipedal bulliform $( \pm 9,4 \%)$, Cuneiform bulliform $( \pm 2,5 \%)$, Cross $( \pm 2,5 \%)$ e Elongate psilate $( \pm 1,4 \%)$ aparecem como elementos subordinados.

Os valores do índice Ic variaram de $5,7 \%(5 \mathrm{~cm})$ a $24 \%(20 \mathrm{~cm})$, e o valor do Iph obtido para a amostra do topo foi de $0,86 \%$. Os valores para ambos os índices foram os menores registrados ao longo do perfil sedimentar. Dessa forma, é possível inferir a partir dos índices Ic e Iph o predomínio de gramíneas $\mathrm{C}_{4}$ em ambiente quente e úmido (Twiss 1992, Fredlund \& Tieszen 1994, Bremond et al. 2005). Dentre os morfotipos de Poaceae taxonomicamente identificados para este intervalo, os fitólitos de Panicoideae são predominantes. De acordo com Barboni et al. (1999), gramíneas Panicoideae são abundantes ao longo das margens dos rios e em locais temporariamente alagados.

Os valores da razão D/P variaram de $3,4(30 \mathrm{~cm})$ a $0,76(5 \mathrm{~cm})$, refletindo a tendência da diminuição da densidade arbórea, e a formação de vegetação aberta no topo do perfil. Valores de D/P menores que 1 foram descritos para áreas de campos e Cerrado no Brasil (e.g. Alexandre et al. 1999, Calegari 2008, Calegari et al. 2013, Coe et al. 2014a). A amostra de 0 a $5 \mathrm{~cm}$ reflete a atual vegetação na área de estudo, que é caracterizada por áreas de pastagens e com influência antrópica. Com relação ao índice $\mathrm{Bi}$, os valores registrados variaram de $21 \%(30 \mathrm{~cm})$ a $0,8 \%(5 \mathrm{~cm})$. Estes valores, tal como para os demais índices fitolíticos, foram os menores ao longo de todo o perfil sedimentar. Após 143 anos cal AP, é possível observar uma diminuição do estresse hídrico das plantas, e consequentemente, o aumento na disponibilidade de água no solo.

Cohen et al. (2014) analisaram o conteúdo polínico das amostras deste intervalo, e registraram o predomínio de elementos herbáceos (30-100\%) como Poaceae (30-60\%), Cyperaceae (9-40\%) e Asteraceae (0-7\%), além de árvores e arbustos evidenciados por Fabaceae (0-50\%) e Sapotaceae (0-17\%), refletindo assim uma vegetação predominantemente composta por ervas. As amostras dos outros intervalos holocênicos deste trabalho não apresentaram conteúdo polínico.

No estudo da Lagoa do Macuco, vale do Rio Barra Seca, Buso Junior et al. (2013a) observaram altos valores percentuais de plantas aquáticas entre 1287 e 585 cal anos AP. Além disso, os autores descreveram que a partir de $\sim 600$ anos cal AP a área de estudo era colonizada principalmente por Cyperaceae e plantas aquáticas tais como Potamogeton spp., Salvinia spp. e Nymphaeaceae/Pontederiaceae, e refletiram o estabelecimento da lagoa de água doce e da planície de inundação do Rio Barra Seca.

Da mesma forma, os dados da assembléia fitolítica apresentaram os maiores valores percentuais de fitólitos do tipo Papillae (Cyperaceae) e indicativos de disponibilidade de água no solo, provavelmente devido a períodos de extravasamento da Lagoa Bonita. Por essa razão, interpretou-se que a atual paisagem, de vegetação herbácea, antropizada e com disponibilidade de água no solo, foi estabelecida durante os últimos $\sim 200$ anos.

\section{Conclusões}

Através das assembléias de fitólitos foi possível verificar as mudanças na vegetação, com inferências climáticas para o Holoceno na costa norte do estado do Espírito Santo:

- Entre 7589 anos cal AP e 5441 anos cal AP (idade interpolada), fitólitos de dicotiledôneas e gramíneas foram predominantes. Os valores de D/P $(3,9$ - 9,7), Ic $(44,4 \%$ - 88,8\%) e Iph $(4,5 \%$ - 6,6\%) sugeriram uma vegetação composta por árvores e por gramíneas $\mathrm{C}_{3}$ e $\mathrm{C}_{4}$, sob condições climáticas quentes e úmidas. $\mathrm{O}$ índice $\mathrm{Bi}(23 \%$ - 68\%) indicou estresse salino, possivelmente devido ao processo marinho transgressivo no Holoceno. É provável que a vegetação fosse semelhante à de restinga, que ocorre atualmente sobre depósitos litorâneos arenosos.

- Para o intervalo de 5441 anos cal AP (idade interpolada) a 143 anos cal AP, os morfotipos de Poaceae e dicotiledôneas foram predominantes, e os índices Ic (39\% - 90\%) e Iph $(5 \%)$ indicaram a presença de gramíneas $\mathrm{C}_{3}$ e $\mathrm{C}_{4}$ em ambiente quente e úmido. Os valores de $\mathrm{D} / \mathrm{P}(3,4-17,8)$ e $\mathrm{Bi}(29 \%-88 \%)$ sugeriram oscilações na densidade arbórea e na ocorrência de períodos intercalados de maior e menor estresse hídrico, indicando assim, um clima sazonal. A vegetação provavelmente era um mosaico com diferentes formações vegetais da restinga, com elementos arbóreos e herbáceos.

- Durante os últimos 200 anos (Intervalo 3 - < 143 anos cal AP), o predomínio de fitólitos de dicotiledôneas e Poaceae, e os valores de Iph $(0,8 \%)$, Ic $(5,7 \%-20,5 \%), \mathrm{D} / \mathrm{P}(0,7-3,4)$ e $\mathrm{Bi}(0,8 \%$ - $21 \%)$ registrados, indicaram o predomínio de gramíneas $\mathrm{C}_{4}$ em ambiente quente e úmido, com disponibilidade de umidade no solo, e a formação de uma vegetação predominantemente herbácea no topo do perfil, refletindo a atual área coberta por pastagens.

Apesar da importância do uso dos fitólitos em estudos de reconstituição paleoambiental, poucos são os estudos publicados para o Brasil. Dessa forma, além deste trabalho ser uma contribuição inédita no que diz respeito à análise fitolítica na costa do Espírito Santo, os dados corroboram com estudos polínicos anteriormente publicados sobre o clima quente e úmido durante o Holoceno para a região.

\section{Agradecimentos}

Os autores agradecem a Reserva Natural Vale (Linhares, ES, Brasil) pelo apoio nos trabalhos de 
campo e aos técnicos do Laboratório de ${ }^{14} \mathrm{C}$ do CENAUSP, Liz Moraes e Thiago Campos, pelo auxílio na preparação das amostras para as datações AMS. Este trabalho foi financiado pela Fundação de Amparo à Pesquisa do Estado de São Paulo - FAPESP, processo 2011/00995-7, e pelo Conselho Nacional de Desenvolvimento Científico e Tecnológico - CNPq, processo 470210/2012-5. O primeiro autor agradece a FAPESP pela bolsa de doutorado (processo 2010/52606-1).

\section{Referências bibliográficas}

Alexandre A., Meunier J-D., Lézine A.M., Vincens A., Schwartz D. 1997. Phytoliths: indicators of grassland dynamics during the late Holocene in intertropical Africa. Palaeogeography, Palaeoclimatology, Palaeoecology, 136:213-229.

Alexandre A., Meunier J-D., Mariotti A., Soubies F. 1999. Late Holocene phytolith and carbon-isotope record from a latosol at Salitre, South-Central Brazil. Quaternary Research, 51:187-194.

Amaral P.G.C., Giannini P.C.F., Sylvestre F., Pessenda L.C.R. 2012. Paleoenvironmental reconstruction of a Late Quaternary lagoon system in southern Brazil (Jaguaruna region, Santa Catarina state) based on multi-proxy analysis. Journal of Quaternary Science, 27:181-191.

Angulo R.J., Lessa G.C., Souza M.C de. 2006. A critical review of mid- to late-Holocene sea-level fluctuations on the eastern Brazilian coastline. Quaternary Science Reviews, 25:486-506.

Barboni D., Bonnefille R., Alexandre A., Meunier J.D. 1999. Phytoliths as paleoenvironmental indicators, West Side Middle Awash Valley, Ethiopia. Palaeogeography, Palaeoclimatology, Palaeoecology, 152:87-100.

Blinnikov M., Busacca A., Whitlock C. 2002. Reconstruction of the late Pleistocene grassland of the Columbia basin, Washington, USA, based on phytolith records in loess. Palaeogeoghaphy, Palaeoclimatology, Palaeoecology, 177:77-101.

Borba-Roschel M., Alexandre A., Varajão A.F.D.C., Meunier J. D., Varajão C.A.C., Colin F. 2006. Phytoliths as indicators of pedogenesis and paleoenvironmental changes in the brazilian cerrado. Journal of geochemical exploration, 88:172-176.

Bremond L., Alexandre A., Hély C., Guiot, J. 2005. A phytolith index as a proxy of tree cover density in tropical areas: calibration with Leaf Area Index along a forest-savanna transect in southern Cameroon. Global and Planetary Change, 45:277293.

Buso Junior A.A., Pessenda L.C.R., De Oliveira P.E., Cohen M.C.L., Giannini P.C.F., Schiavo J.A., Rossetti D.F., Volkmer-Ribeiro C., Oliveira S.M.B., Lorente F.L., Borotti Filho M.A., Bendassolli J.A., Siqueira J.S. 2013a. Late Pleistocene and Holocene vegetation and climate dynamics and Amazonian taxa at Atlantic Rainforest - Linhares, ES, southeastern Brazil. Radiocarbon, 55:1747-1762.

Buso Junior A.A., Pessenda L.C.R., De Oliveira P.E., Giannini P.C. F., Cohen M.C.L., Volkmer-Ribeiro C., Oliveira S.M.B., Favaro D.I.T., Rossetti D.F., Lorente F.L., Borotti Filho M.A., Schiavo J.A., Bendassolli J.A., Siqueira J.S. 2013b. From an estuary to a freshwater lake: a paleo-estuary evolution in the context of Holocene sea-level fluctuations, southeastern Brazil. Radiocarbon, 55:1735-1746.

Calegari M.R. 2008. Ocorrência e significado paleoambiental do horizonte A húmico em latossolos. Tese de Doutorado. PósGraduação em Agronomia, Escola Superior de Agricultura Luiz de Queiroz, Universidade de São Paulo, 259 p.

Calegari M. R., Madella M., Vidal-Torrado P., Pessenda L.C.R., Marques F.A. 2013. Combining phytoliths and $\delta^{13} \mathrm{C}$ matter in Holocene paleoenvironmental studies of tropical soils: an example of an oxisol in Brazil. Quaternary International, 287:4755.

Campos A.C de., Labouriau L.G. 1969. Corpos silicosos de gramíneas dos Cerrados. II. Pesquisa Agropecuária Brasileira, 4:143-151

Castro D.F., Rossetti D.F., Cohen M.C.L., Pessenda L.C.R., Lorente F.L. 2013. The growth of the Doce River Delta in northeastern Brazil indicated by sedimentary facies and diatoms. Diatom Research, 28:455-466.
Coe H.H.G., Alexandre A., Carvalho C.N., Santos G.M., Silva A. S., Sousa L.O.F., Lepsch I.F. 2013. Changes in Holocene tree cover density in Cabo Frio (Rio de Janeiro, Brazil): evidence from soil phytolith assemblages. Quaternary International, 287:63-72.

Coe H.H.G., Macario K., Gomes J.G., Chueng K.F., Oliveira F., Gomes P.R.S., Carvalho C., Linares R., Alves E., Santos G.M. 2014a. Understanding Holocene variations in the vegetation of São Joao River basin, southeastern coast of Brazil, using phytolith and carbon isotopic analyses. Palaeogeography, Palaeoclimatology, Palaeoecology, 415:59-68.

Coe H.H.G., Gomes J.G., Macario K. 2014b. Understanding the origin and evolution of soil profiles in the São João River basin, Rio de Janeiro, Brazil. In: Coe H.H.G., Osterrieth M. (eds) Synthesis of some phytoliths studies in South America (Brazil and Argentina). Nova Science Publishers, New York, 171-192p.

Coe H.H.G., Augustin C.H.R., Chueng K.F. 2014c. Applications of phytolith studies in a geomorphic sequence in the Espinhaço mountain range, Brazil. In: Coe H.H.G., Osterrieth M. (eds) Synthesis of some phytoliths studies in South America (Brazil and Argentina). Nova Science Publishers, New York, 193-213p.

Cohen M.C.L., França M.C., Rossetti D.F., Pessenda L.C.R., Giannini P.C.F., Lorente F.L., Buso Junior A.A., Castro D., Macario K. 2014. Landscape evolution during the late Quaternary at the Doce River mouth, Espírito Santo State, Southeastern Brazil. Palaeogeography, Palaeoclimatology, Palaeoecology, 415:48-58.

Das S., Ghosh R., Paruya D.K., Yao Y-F., Li C-S., Bera S. 2014. Phytolith spectra in respiratory aerial roots of some mangrove plants of the Indian Sunderbans and its efficacy in ancient deltaic environment reconstruction. Quaternary International, 325:179. 196.

Diester-Haas L., Schrader H.J., Thiede J. 1973. Sedimentological and paleoclimatological investigations of two pelagic ooze cores off Cape Barbas, North-West Africa. Meteor Forsch-Ergebnisse, 16:19-66.

Epstein E. 1994. The anomaly of silicon in plant biology. Proceedings of the National Academy of Sciences, 91:11-17.

Evin J., Marechal J., Pachiaudi C. 1980. Conditions involved in dating terrestrial shells. Radiocarbon 22:545-555.

França R.L., Del Rey A.C., Tagliari C.V., Brandão J.R., Fontanelli P. de R. 2007. Bacia do Espírito Santo. Boletim de Geociências da Petrobrás, 15:501-509.

França M.C., Cohen M.C.L., Pessenda L.C.R., Rossetti D.F., Lorente F.L. Buso Junior A.A., Guimarães J.T.F., Friaes Y., Macario K. 2013. Mangrove vegetation changes on Holocene terraces of the Doce River, southeastern Brazil. Catena, 110:59-69.

Fredlund G.G., Tieszen L.T. 1994. Modern phytolith assemblages from the North American great plains. Journal of Biogeography, 21:321-335.

Goodfriend G.A., Stipp J.J. 1983. Limestone and the problem of radiocarbon dating of land-snail shell carbonates. Geology, 11:575-577.

Goodfriend G.A. 1987. Radiocarbon age anomalies in shell carbonate of land snails from semi-arid areas. Radiocarbon, 29:159-167.

Grigore M-N., Toma C., Boscaiu M. 2010. Ecological implications of bulliform cells on halophytes, in salt and water stress natura conditions. Studia Universitatis Vasile Goldis Seria Stiintele Vietti, 21:5-15.

Grimm E.C. 1987. CONISS: a fortram 77 program for stratigraphically constrained cluster analysis by the method of the incremental sum of squares. Computers and Geosciences, 13:13-35.

Gutiérrez M.A., Martínez G., Luchsinger H., Grill S., Zucol A.F., Hassan G.S., Barros M.P., Kaufmann C.A., Álvarez M.C. 2011. Paleoenvironments in the Paso Otero locality during Late Pleistocene-Holocene (Pampean region, Argentina): an interdisciplinary approach. Quaternary International, 245:37-47.

Hammer Ø., Harper D.A.T., Ryan P.D. 2001. PAST: paleontological statistics software package for education and data analysis. Palaeontologia Electronica 4:1-9.

Harper C.W. 1984. Improved methods of facies sequence analysis, In: Walker R.G. (eds) Facies Models. Geological Association of Canada, Ontario, 11-13p.

IBGE - Instituto Brasileiro de Geografia e Estatística. 1987. Carta do Brasil. Folha SE-24 Rio Doce: geologia, geomorfologia, 
pedologia, vegetação, uso potencial da terra. IBGE, Rio de Janeiro, $548 \mathrm{p}$.

IBGE - Instituto Brasileiro de Geografia e Estatística. 2004. Mapa de vegetação do Brasil. Disponível em: http://mapas.ibge.gov.br/vegetação. Acesso em 10 de dezembro 2013.

Iriarte J. 2006. Vegetation and climate change since $14,81014 \mathrm{C}$ yr B.P. in southeastern Uruguay and implications for the rise of early formative societies. Quaternary Research, 65:20-32.

Kelly E.F., Blecker S.W., Yonker C.M., Olson C.G., Wohl E.E., Todd L.C. 1998. Stable isotope composition of soil organic matter and phytoliths as paleoenvironmental indicators. Geoderma, 82:59-81.

Köppen W. 1948. Climatologia: con un studio de los climas de la tierra. Fondo de Cultura Econômica, México, 479p.

Ledru M.P., Salgado-Labouriau M.L., Lorscheitter M.L. 1998. Vegetation dynamics in Southern and Central Brazil during the last 10,000 yr. BP. Review of Palaeobotany and Palynology, 99:131-42.

Lisboa L. de P. 2006. Paleoecologia e bioestratigrafia em foraminíferos do talude continental da Bacia do Espírito Santo: estudo em dois "piston cores". Monografia de Conclusão de Curso em Oceanografia. Universidade Federal do Espírito Santo, $76 \mathrm{p}$.

Lorente, F.L., Pessenda L.C.R., Oboh-Ikuenobe F., Buso Jr A.A., Cohen M.C.L., Meyer K.E.B., Giannini P.C.F., De Oliveira P.E., Rossetti D.F., Borotti Filho M.A., França M.C., Castro D.F., Bendassolli J.A., Macario K. 2014. Palynofacies and stable C and $\mathrm{N}$ isotopes of Holocene sediments from Lake Macuco (Linhares, Espírito Santo, southeastern Brazil): depositional settings and palaeoenvironmental evolution. Palaeogeography, Palaeoclimatology, Palaeoecology, 415:69-82.

Lu H., Liu K. 2003. Morphological variations of lobate phytoliths from grasses in China and the Southeastern USA. Diversity and distributions, 9:73-87.

Madella M., Alexandre A., Ball T. 2005. International Code for Phytolith Nomenclature 1.0. Annals of Botany, 96:253-260.

Meyers P.A. 1994. Preservation of elemental and isotopic source identification of sedimentary organic matter. Chemical Geology 114:289-302

Meyers P.A. 1997. Organic geochemical proxies of paleoceanographic, paleolimnologic, and paleoclimatic processes. Organic Geochemistry, 27:213-250.

Miall A.D. 1978. Facies types and vertical profile models in braided river deposits: a summary. In: MIALL A.D. (eds) Fluvial Sedimentology. Canadian Society of Petroleum Geologists, Calgary, 597-604p

Nascimento T. de C. 2012. Reconstituição da história quaternária da Mata Atlântica na região Centro-Norte do estado do Espírito Santo. Dissertação de Mestrado. Pós-Graduação em Análise Geoambiental, Universidade de Guarulhos, 294p.

Osterrieth M., Madella M., Zurro D., Alvarez M.F. 2009. Taphonomical aspects of sílica phytoliths in the loess sediments of the Argentinean pampas. Quaternary International, 193:70-79.

Parolin M., Rasbold G.G., Pessenda L.C.R. 2014. Paleoenvironmental conditions of Campos Gerais, Paraná, since the Late Pleistocene, based on phytoliths and $\mathrm{C}$ and $\mathrm{N}$ isotopes. In: Coe H.H.G., Osterrieth M. (eds) Synthesis of some phytoliths studies in South America (Brazil and Argentina). Nova Science Publishers, New York, 149-170p.

Pearsall D.M., Chandler-Ezell K., Chandler-Ezell A. 2003. Identifying maize in neotropical sediments and soils using cob phytoliths. Journal of Archaeological Science, 30:611-627.

Pereira O.J. 1990. Caracterização fitofisionômica da restinga de Setiba-Guarapari-Espírito Santo. In: ACIESP (eds) $2^{\circ}$ Simpósio sobre ecossistemas da costa sul e sudeste brasileira. Anais, 3:207-219.

Pessenda L.C.R., Vidotto E., De Oliveira P.E., Buso Jr A.A., Cohen M.C.L., Rossetti D.F., Ricardi-Branco F., Bendassolli J.A. 2012. Late Quaternary vegetation and coastal environmental changes at Ilha do Cardoso mangrove, southeastern Brazil. Palaeogeography, Palaeoclimatology, Palaeocology, 363364:57-68.

Pigati J.S., Mcgeehin J.P., Muhs D.R., Bettis E.A. 2013. Radiocarbon dating late Quaternary loess deposits using small terrestrial gastropod shells. Quaternary Science Reviews, 76:114-128.
Piperno D.R. 1988. Phytolith analysis: an archaeological and geological perspective. Academic Press, London, 280p.

Piperno D.R. 1991. The status of phytolith analysis in the american tropics. Journal of World Prehistory, 5:155-191.

Piperno D.R., Becker P. 1996. Vegetational history of a site in the Central Amazon basin derived from phytolith and charcoal records from natural soils. Quaternary Research, 45:202-209.

Piperno D.R. 2006. Phytoliths: a comprehensive guide for archaeologists and paleoecologists. Altamira Press, Oxford, $237 \mathrm{p}$.

Raitz E. 2012. Coleção de referência de silicofitólitos da flora do sudoeste do Paraná: subsídios para estudos paleoambientais. Dissertação de Mestrado. Pós-graduação em Geografia, Universidade Estadual do Oeste do Paraná, 204 p.

Rapp Jr G., Mulholland S.C. 1992. Phytolith systematics: emerging issues. Plenum Press, New York, 350p.

Reimer P.J., Baillie M.G.L., Bard E., Bayliss, A., Beck J.W., Blackwell P.G., Bronk Ramsey C., Buck C.E., Burr G.S., Edwards R.L., Friedrich M., Grootes P.M., Guilderson T.P., Hadjas I., Heaton T.J., Hogg A.G., Hughen K.A., Kaiser K.F., Kromer B., Mccormac F.G., Mannin S.W., Reimer R.W., Richards D.A., Southon J.R., Talamo S., Turney C.S.M., Van Der Plicht J., Weyhenmeyer C.E. 2009. IntCal09 and Marine09 radiocarbon age calibration curves, 0-50,000 years cal BP. Radiocarbon 51:1111-1150.

Rovner I. 1971. Potential of opal phytoliths for use in paleoecological reconstruction. Quaternary Research, 1:343-349.

Rubin M., Likins R.C., Berry E.G. 1963. On the validity of radiocarbon dates from snail shells. Journal of Geology 71:8489.

Scott L. 2002. Grassland development under glacial and interglacial conditions in southern Africa: review of pollen, phytolith and isotope evidence. Palaeogeography, Palaeoclimatology, Palaeoecology, 177:47-57.

Sendulsky T., Labouriau L.G. 1966. Corpos silicosos de gramíneas dos Cerrados. I. Anais da Academia Brasileira de Ciências, 38:159-170.

Stanley D.J., Hait A.K. 2000. Deltas, radiocarbon dating, and measurements of sediment storage and subsidence. Geology, 28:295-298.

Strömberg C.A.E., Werdelin L., Friis E.M., Saraç G. 2007. The spread of Grass-dominated habitats in Turkey and surrounding areas during the Cenozoic: phytolith evidence. Palaeogeography, Palaeoclimatology, Palaeoecology, 250:18-49.

Suguio K., Martin L. 1981. Significance of Quaternary sea-level fluctuations for delta construction along the Brazilian coast. Geo-marine letters, 1:181-185.

Suguio K., Martin L., Dominguez J.M.L. 1982. Evolução da planície costeira do Rio Doce (ES) durante o Quaternário: influência das flutuações do nível do mar. In: Simpósio do Quaternário do Brasil, 4, 1982, Rio de Janeiro. Anais... Rio de Janeiro: Simpósio do Quaternário do Brasil, 1982. p. 93-116.

Suguio K., Martin L. 1990. Geomorfologia das restingas. In: ACIESP (eds) $2^{\circ}$ Simpósio sobre ecossistemas da costa sul e sudeste brasileira. Anais, 3:185-205

Thorn V.C. 2004. Phytolith evidence for C4-dominated grassland since the early Holocene at Long Pocket, northeast Queensland, Australia. Quaternary Research, 61: 168-180.

Trombold C.D., Israde-Alcantara I. 2005. Paleoenvironment and plant cultivation on terraces at La Quemada, Zacatecas, Mexico: the pollen, phytolith and diatom evidence. Journal of Archaeological Science, 32:341-353.

Twiss P.C., Suess E., Smith R.M. 1969. Morphological classification of grass phytoliths. Soil Science Society of America Proceedings, 33:109-115.

Twiss P.C. 1987. Grass opal phytoliths as climatic indicators of the Great Plains Pleistocene. In: JOHNSON W.C. (eds) Quaternary Environments of Kansas. Kansas Geological Survey Guidebook, EUA, 179-188p.

Twiss P.C. 1992. Predicted world distribution of C3 and C4 grass phytoliths. In: Rapp Jr G., Mulholland S.C. (eds) Phytolith systematics. Emerging Issues, Advances in Archeological and museum science. Plenum Press, 113-128p.

Walker R.G. 1992. Facies, facies models and modern stratigraphic concepts. In: Walker R.G., James N.P. (eds) Facies Models Response to Sea Level Change. Geological Association of Canada, Ontario, 1-14p. 
Quaternary and Environmental Geosciences (2015) 06(1):26-40

Estudos ambientais sobre a vegetação e o clima no Holoceno

Watling J., Iriarte J. 2013. Phytoliths from the coastal savannas of French Guiana. Quaternary International, 287:162-180.

Recebido 18 de abril de 2014

Aceito 06 de fevereiro de 2015 